\title{
MATH OUTSIDE THE BUBBLE
}

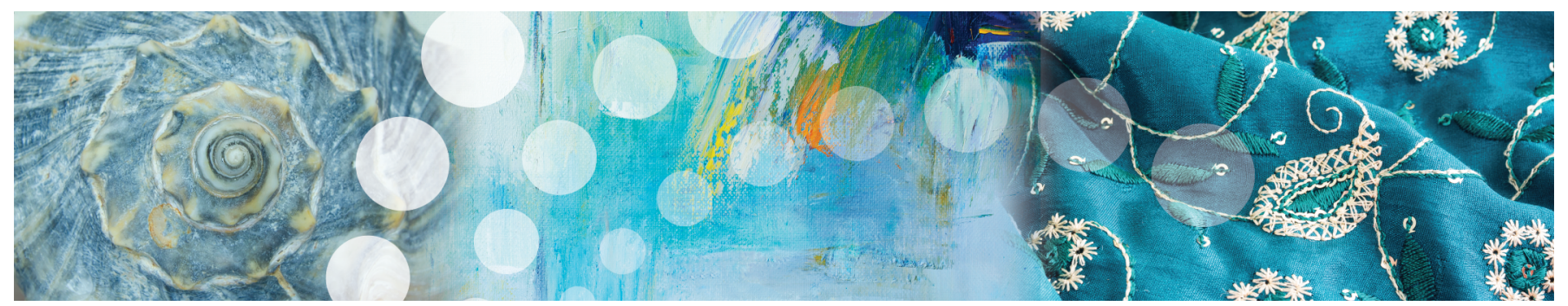

\section{Problems That Feel Like Play: Sidewalk Math as Pandemic-Era Diversion}

\section{Sophia D. Merow}
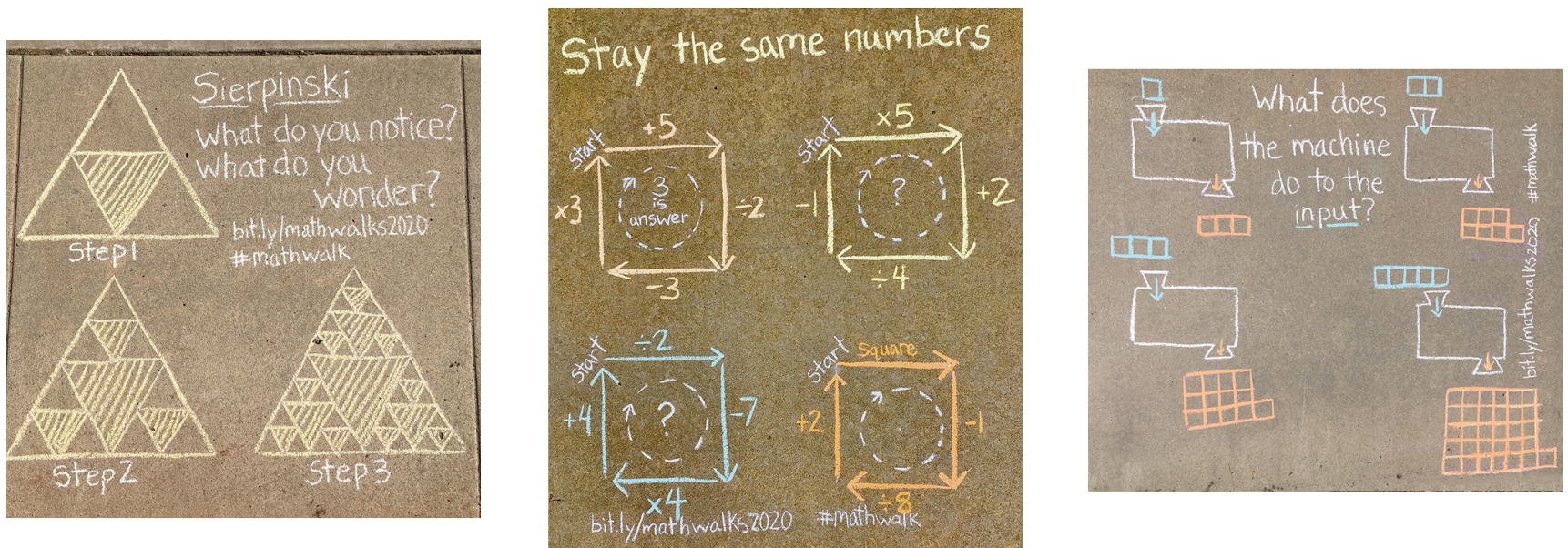

Figure 1. A selection of Traci Jackson's Math Walk chalkings.

Traci Jackson looks at sidewalks differently now. She evaluates surface texture and estimates foot traffic. She anticipates shadows and checks for sprinklers. And when she finds a stretch of sidewalk sufficiently smooth, sunlit, and in the public eye, Jackson sets to work: on hands

Sophia D. Merow is a freelance writer and editor. Her email address is sdmerow@gmai 1 . com.

For permission to reprint this article, please contact: reprint-permission aams.org.

DOI: https://dx.doi.org/10.1090/noti2282 and knees, she chalks a colorful combination of words, numbers, symbols, and diagrams calculated to prompt mathematical musings among passersby. Another Math Walk-accomplished.

Jackson is not the first to juxtapose the words "math" and "walk," of course, nor the first to exchange a blackboard for an expanse of concrete or asphalt. In 2013, educators and artists from Lesley University launched the Sidewalk Math project (www . sidewa 7 kmath . com) to "engage young children in learning mathematical patterns by walking, 


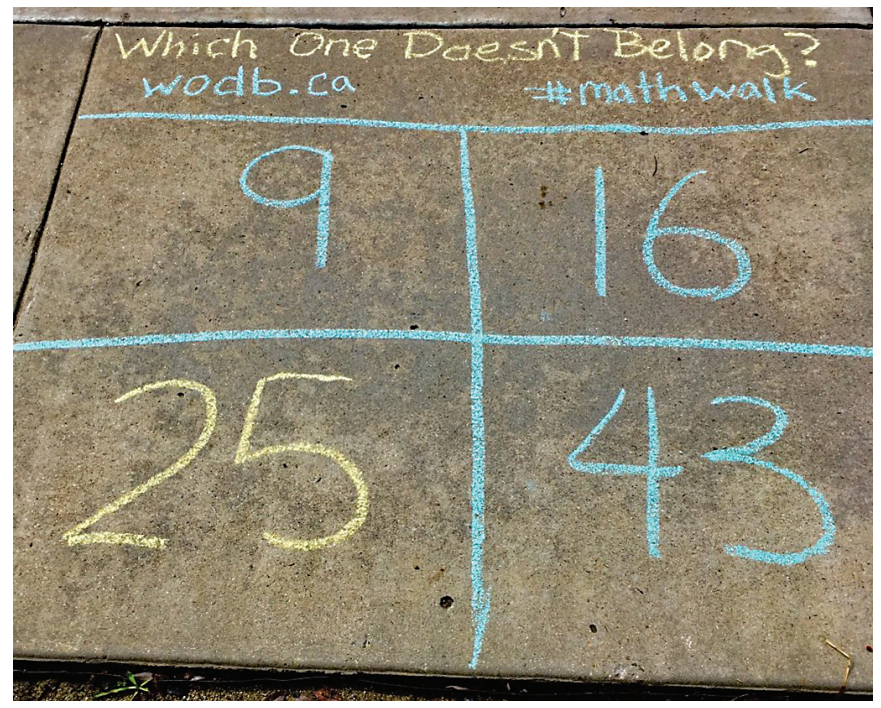

Figure 2. Jackson's first Math Walk offering, March 27, 2020.

hopping, jumping, and skipping through colorful designs on the sidewalk." As part of its 100th anniversary celebration in 2015, the Mathematical Association of America debuted the website MathWalkDC (see https://bit.7y /3g1FR4b), which guided visitors to the nation's capital through a selection of the city's more mathematically noteworthy landmarks-the 19-degree angle on one corner of the East Building of the National Gallery of Art, for instance. Bronx Center for Science and Mathematics teacher Brian Palacios, himself a longtime practitioner of sidewalk math, has proposed (see https://bit. 1y/3gfPxgy) that math education conferences give back to host cities by tagging up thoroughfares with thought-provoking problems.

In late March of 2020, however, Traci Jackson was not yet aware of the above. On a walk in her southern California neighborhood, she observed a mom running her kids through some drills. "Go to the corner and do five jumping jacks," the parent-turned-PE-instructor directed. "Now three windmills." Might other school subjects be integrated into the daily constitutionals staving off stir-craziness during quarantine? Jackson wondered. A secondary math teacher at San Diego's Poway Unified School District, Jackson had been intrigued by the idea of public problem-solving since reading about Minneapolis math teacher Sara VanDerWerf stimulating sometimes heated discussion with accessible-to-all problems posted in the hallway outside her classroom under a "Can You Solve This?" placard (see https://bit. 1y/37gfNEW). For a few years pre-pandemic Jackson had reposted VanDerWerf's problems in her own school and been gratified to see students, teachers, and parents alike engage in spontaneous for-its-own-sake problem-solving.

"If I could leave a little bit of math on daily walks," Jackson wrote in an online account of how she started math walking, "I could not only give parents a way to incorporate some math, but maybe I could try and change math into curiosity, wonder and problem solving, even just a little."
On March 27, armed with some leftover chalk, a vague recollection of a \#mathgraffiti hashtag, and a Which One Doesn't Belong (see https: //wodb.ca/) problem, Jackson began the practice she has continued ever since (see Figure 2).

Jackson has kept up the Math Walk habit as long as she has-going on 13 months-because of how successful her chalkings have proven at encouraging mathematical discussion. Jackson's neighbors confer audibly in the street about her offerings. They snap photos of the sidewalk math-to ponder later, to talk about with their kids after dinner, to share via email with far-flung relatives. One woman told Jackson that her husband only started joining her on daily walks to track down and wrestle with the latest problem.

One day a pedestrian stopped to thank Jackson, wielding a makeshift mega-compass jerry-rigged from a piece of string, for her work. She was visiting for her father's funeral, the woman explained, and had found in the sidewalk math a welcome if intermittent escape from the grief that otherwise consumed her. "This moved me so much we stood six feet away with tears in our eyes making a strong human connection," Jackson recalls.

And because she documents her Math Walks on Twitter (@traciteacher), Facebook (www.facebook.com/groups /mathwa1ks), and a dedicated website (https://bit.7y /mathwa1ks2020), Jackson has been able to connect with would-be problem posers and solvers from far beyond the estimated one-mile radius of her on-foot travels. The youngster behind the YouTube channel MSK Coding posted

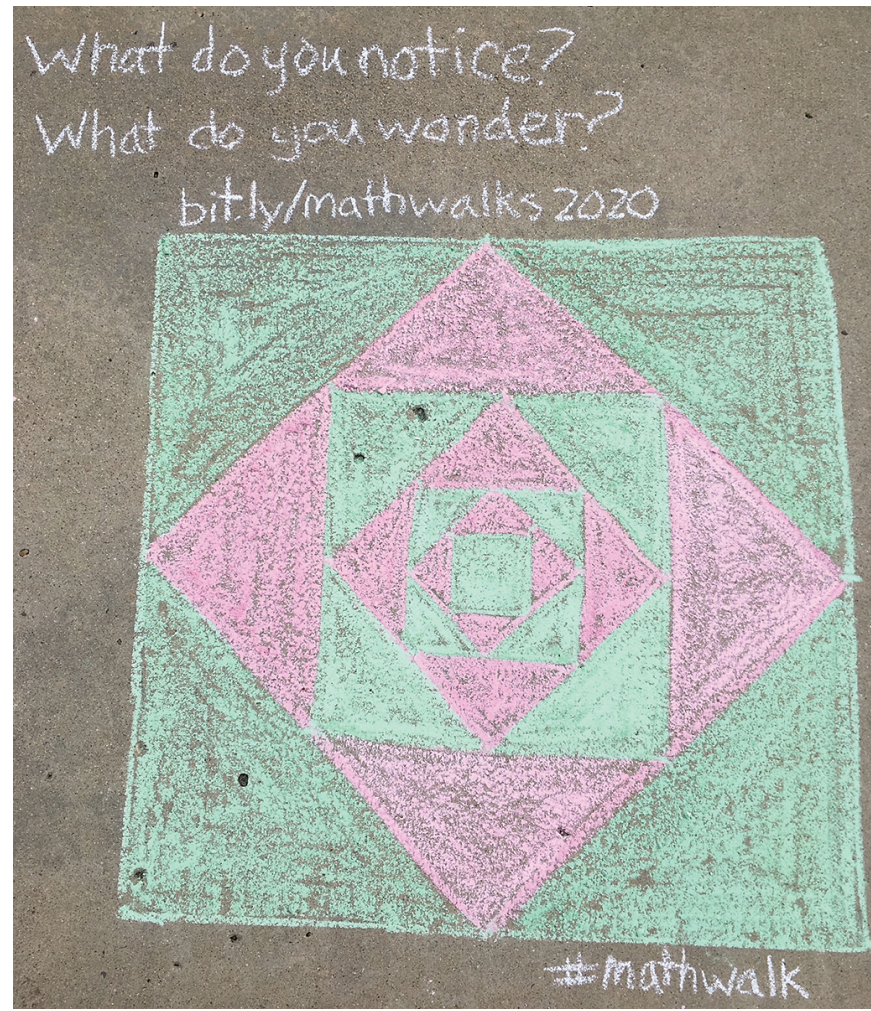

Figure 3. Jackson's April 13 chalking. 


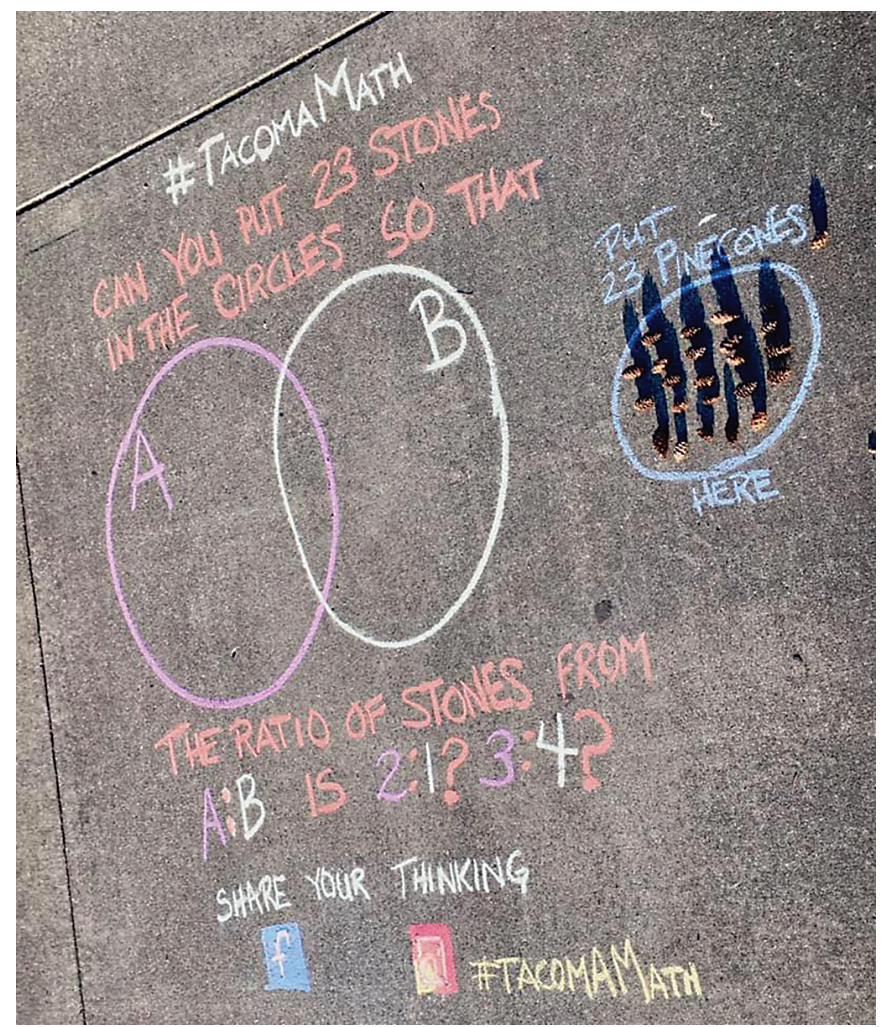

Figure 4. One of Jennifer Quinn's chalkings.

a video (see https://bit. 1y/2LJP778) about using Python to explore the fractal-like drawing Jackson chalked on April 13 (see Figure 3). Educators across the country (and the world: Belgium-based math teacher Clara Huizink maintains a French version of Jackson's site) retweet Jackson's posts, replicate her chalkings, and are moved by her efforts to undertake math walks of their own. "Started using @traciteacher inspired \#mathwalks in front of my house and just caught an adult and child with flashlights scoping them out," tweeted Massachusetts teacher Lisa Beauchemin in September. "At 9pm. On Saturday night. I couldn't love it more."

Brian Palacios is not surprised that sidewalk math took off during the pandemic. Outdoor, inherently local, and educational but enjoyably so, sidewalk math is a diversion well suited to the COVID era. And, according to Palacios, "the more sidewalk math, the better." A salutary, childlike joy awaits the sidewalk chalker, for one thing, and the act also furthers a worthy external-to-self cause. "Math desperately needs advocacy that goes beyond the classroom," he says. "Inviting, public-facing displays of math-like sidewalk math-is a great way to do just that."

Some problems lend themselves more than others, of course. Palacios aims for accessible, "low floor, high ceiling" problems that can be presented simply. "My favorite problems are visually appealing, have more than one possible answer, and lead to more questions," says Mathematical Association of America president and University of Washington Tacoma combinatorialist Jennifer Quinn, who has done some Jackson-inspired chalking (see Figure 4) as part of Tacoma's STEAM Learning Collaborative Action Network.

Jackson looks for "problems that feel like play"-see the list below for a selection of her go-to sources-and has some pro tips for Math Walk novices. Regular chalk has more staying power than sidewalk chalk. Purple chalk doesn't show up well and is thus useful for drafting. A scrap of old washcloth makes an excellent eraser.

And "take a mask," Jackson advises, because "people will stop to talk to you and it is wonderful."

\section{Some Sources of Math Walk Inspiration}

Art of Problem Solving, https://artofproblemsolving .com/keeplearning

Brilliant, https://briliant.org/

Don Steward, https://donsteward.blogspot. com/

Fraction Talks, www. fractiontalks.com/

Graphing Stories, www.graphingstories.com/index.htm 1

Julia Robinson Mathematics Festival, https://www.jrmf .org/

Mathcommunities.org, https://mathcommunities.org/

Mathcurious, https://mathcurious.com/

Math for Love, https://mathforlove.com/lessons/

Math Is Visual, https://mathisvi sual.com/

MathsChallenge.net, https://mathschallenge.net/

Open Middle, https: //www. openmiddle.com/

Play With Your Math, https://playwi thyourmath.com/

Same or Different?, https://samedifferentimages.word press.com/

Thinking Mathematics!, www. jamestanton.com/

Visual Patterns, www. vi sualpatterns.org/

Which One Doesn't Belong?,https://wodb.ca/

Would You Rather Math,https://www. wouldyourathermath . com/

youcubed, https://www. youcubed.org/

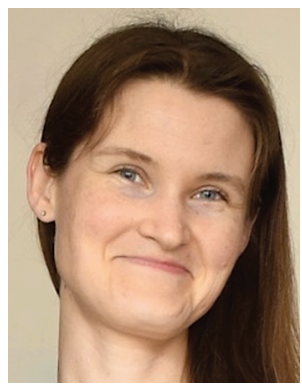

Sophia D. Merow

\section{Credits}

Figures 1-3 are courtesy of Traci Jackson. Figure 4 is courtesy of Jennifer Quinn. Author photo is by Igor Tolkov. 